Tohoku J. Exp. Med., 2004, 203, 69-76

\title{
A Mutation of the Glucocorticoid Receptor Gene in Patients with Systemic Lupus Erythematosus
}

\author{
Young Moo Lee, Junko Fujiwara, ${ }^{1}$ Yasuhiko Munakata, ${ }^{2}$ Tomonori Ishit, ${ }^{2}$ \\ Akira Sugawara, ${ }^{3}$ Mitsuo Kaku, ${ }^{1}$ Shoichi Kokubun, Takeshi Sasaki ${ }^{2}$ and Tadao \\ FUNATO $^{1}$ \\ Department of Orthopedics, ${ }^{I}$ Department of Molecular Diagnostics, ${ }^{2}$ Depart- \\ ment of Rheumatology and Hematology, and ${ }^{3}$ Department of Nephrology, Endo- \\ crinology, and Vascular Medicine, Tohoku University, School of Medicine, \\ Sendai 980-8574
}

Lee, Y. M., Fujiwara, J., Munakata, Y., Ishit, T., Sugawara, A., Kaku, M., Kokubun, S., Sasaki, T. and Funato, T. A Mutations of the Glucocorticoid Receptor Gene in Patients with Systemic Lupus Erythematosus. Tohoku. J. Exp. Med., 2004, 203 (2), 69-76 — We screened for mutations of the glucocorticoid receptor (GR) gene in patients with systemic lupus erythematosus (SLE), a typical autoimmune disease. Polymerase chain reaction-single-strand conformation polymorphism analysis (PCR-SSCP) revealed a single mutation in exon 9 of the GR gene in 11/132 (8.3\%) among 66 patients with SLE. No mutations were detected in 52 healthy individuals $(0 / 104,0.0 \%)$, but the same mutation was detected in other autoimmne diseases $(4 / 108,3.7 \%)$. DNA sequencing showed a $T$ to $C$ substitution at codon 766 (position 2430) of the GR gene, which does not alter the amino acid sequence of the GR. Further analysis using a LightCycler generated different melting curves indicates that the pattern with this mutation is different from that of wild type. The identified mutation of the GR gene may represent a polymorphism associated with SLE. — glucocorticoid receptor (GR); mutation; systemic lupus erythematosus (SLE); polymerase chain reaction-single-strand conformation polymorphism (PCR-SSCP); LightCycler (C) 2004 Tohoku University Medical Press

The etiology and pathogenesis of systemic lupus erythematosus (SLE), an autoimmune disease characterized by the production of a variety of autoantibodies (Marion et al. 1994), remains unclear. However, much progress has been made in searching for SLE susceptibility genes, particularly by several genome-wide screening studies
(Gaffney et al. 1998; Arkachaisri and Lehman 1999; Shai et al. 1999). Genetic susceptibility to SLE is undoubtedly complex and presumably involves multiple loci. Linkage of SLE to D1S229 at chromosome 1q41 has been demonstrated in an independent cohort of 127 patients with extended multiplex microsatellite markers (Moser et al.

Received January 28, 2004; revision accepted for publication April 9, 2004.

Address for reprints: Tadao Funato, M.D., Department of Molecular Diagnostics, Tohoku University, School of Medicine, 1-1 Seiryomachi, Aoba-ku, Sendai 980-8574, Japan.

e-mail: tfunato@mail.tains.tohoku.ac.jp 
1999). Candidate genes within this region include PARP, a poly ADP-ribose polymerase that encodes a zinc-finger DNA-binding protein, TGFB2, which encods a transforming growth factor (TGF), and HLX1, which encods a homeobox protein (Tsao et al. 1999). Variant alleles in the mannosebinding lectin (MBL) gene may also be associated with increased susceptibility to SLE and concomitant infections (Garred et al. 1999). Thus, efforts to identify a gene linked to SLE, a non-organ-specific autoimmune disease, are justified.

Glucocorticoids have various effects upon lymphocyte function, including the induction of apoptosis (Schwartzman and Cidlowski 1994; Bamberger et al. 1997). These effects are exclusively mediated by the intracellular glucocorticoid receptor (GR). The GR regulates the expression of human interleukin-2 (IL-2) during glucocorticoid-induced apoptosis (Helmberg et al. 1995; Crispin and Alcocer-Varela 1998). Furthermore, the mechanism by which IL-2 inhibits T-cell function involves a direct interaction between the GR and nuclear factor (Northrop et al. 1992). The production of IL-2 is impaired in SLE (Talal et al. 1982; Russel et al. 1991; Tsokos 1992). In spite of the wide use of corticosteroids in SLE or inflammatory diseases, pathogenetic events such as steroid resistance or drug-induced lupus are poorly defined. The glucocorticoid receptor gene may not be one of the candidate genes identified by genome-wide screening in SLE, but it is interest of whether this receptor is related to steroid sensitivity in SLE. Thus, we investigated whether mutations in exon 5, 7, or 9 of the GR gene are associated with SLE. These exons of the GR gene have previously been identified as hot-spot for mutation in this receptor, which belongs to the large family of nuclear receptors (Karl et al. 1993, 1996; de Lange et al. 1997). These observations prompted us to study the association between the glucocorticoid receptor and autoimmune diseases. The present study investigates whether mutations or polymorphisms in the GR gene are associated with SLE.

\section{Materials ANd Methods}

\section{Patient samples}

Blood samples were obtained from 66 patients (aged 18-72 years) with SLE, 54 patients with autoimmune diseases other than SLE (23 with SLE-like symptoms but not meeting the criteria for diagnosis of SLE, 7 with mixed connective tissue disease [MCTD], 7 with dermatomyositis or polymyositis, 3 with progressive systemic sclerosis, 4 with rheumatoid arthritis, 3 with adult-onset Still's disease [AOSD], 1 with polyarteritis, 2 with Wegener's granulomatosis, 3 with Behçet's disease, 1 with Sjögren's syndrome) and 52 healthy controls (aged 23-48 years). All patients and healthy volunteers gave informed consent to participate in the study. DNA was extracted from blood cells by conventional methods using a SepaGene extraction kit (Sanko Junyaku, Co., Tokyo).

\section{PCR-SSCP analysis}

Primers for the GR gene were prepared on the bassis of the nucleotide sequence of GR cDNA (GeneBank accession number U80946; Karl et al. 1993; Koper et al. 1997) (Table 1). Primers for exons 5, 7 and 9 were synthesized and fluorescence-labeled. The PCR sample mixtures (final volume of $50 \mu \mathrm{l}$ ) included $1 \mu \mathrm{g}$ of DNA, $1 \mathrm{U}$ of Taq DNA polymerase (Toyobo, Co., Tokyo), $25 \mu \mathrm{M}$ of each primer, $1.0 \mathrm{mM}$ of dNTP, and $5 \mu \mathrm{l}$ of reaction buffer. The mixtures were amplified over 30 cycles at $94^{\circ} \mathrm{C}$ for 2 minutes, $55^{\circ} \mathrm{C}$ for 30 seconds and $72^{\circ} \mathrm{C}$ for 90 seconds in a DNA thermal cycler (GeneAmp PCR system 9600: Perkin-Elmer, Foster City, CA, USA) and were then subjected to electrophoresis at $30 \mathrm{~W}$ and $25^{\circ} \mathrm{C}$ on an $8 \%$ polyacrylamide gel for 3hours. The fluorescence of the gel was then read immediately with a FMBIO II Multi-View image analyzer (Hitachi Co., Tokyo)

\section{LightCycler system}

Satisfactory melting curve have been obtained by monitoring the denaturation profile of a 
TABLE 1. Oligonucleotide primers designed for PCR-SSCP and fluorogenic probes for LightCycler system

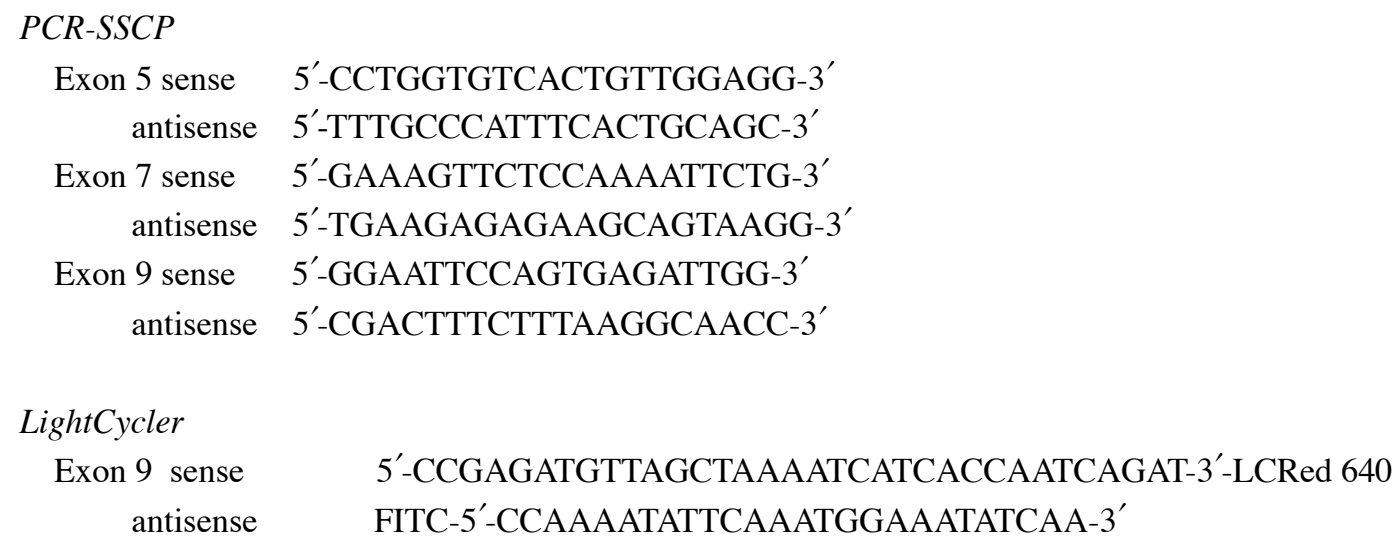

PCR product in the presence of hybridization probes with a LightCycler system (Roche Molecular Biochemicals, Mannheim, Germany). This system may also be used to determine the relative contributions of mutated versus wild-type sequences to signal levels. To analyze the melting curves of PCR mixtures during the present study, sequence-specific fluorescence detectors were prepared from oligonucleotide hybridization probes coupled to a $5^{\prime}$-fluorescein label at the $3^{\prime}$ end (anchor) and to 3'-LightCycler-Red 640 at the $5^{\prime}$ end (mutation). The PCR mixtures included template DNA, Taq DNA polymerase, PCR primers ( $1 \mu \mathrm{l}$ of each), $\mathrm{MgCl}_{2}(25 \mathrm{mM}, 1.6 \mu \mathrm{l})$, a master mixture of deoxynucleotides (dNTPs, $2 \mu 1$ ), the two hybridization probes (mutation $0.4 \mu \mathrm{l}$, anchor $0.8 \mu \mathrm{l})$ and distilled water $(11.2 \mu \mathrm{l})$ per capillary. The mixture was denatured using the LightCycler system at $95^{\circ} \mathrm{C}$ for 60 seconds and amplified over 45 cycles at $94^{\circ} \mathrm{C}$ for 0.1 second, $65^{\circ} \mathrm{C}$ for $10 \mathrm{sec}$ onds, and $72^{\circ} \mathrm{C}$ for 5 seconds, then subjected to a melting step $\left(95^{\circ} \mathrm{C}\right.$ for 0.1 second, $40^{\circ} \mathrm{C}$ for 15 seconds, $85^{\circ} \mathrm{C}$ for 0.1 second) followed by cooling at $40^{\circ} \mathrm{C} 30$ seconds. The level of fluorescence was continuously measured during amplification to monitor the dissociation of the fluorescein-labeled detection probe. The fluorescence signal was plotted in real time against the temperature to produce a melting curve $(T m)$ for each sample. The melting curves were generated by plotting the negative derivative of the fluorescence level with respect to temperature against temperature.

Sequencing analysis

PCR products that exhibited abnormally migrating bands during the PCR-SSCP analysis were subjected to sequencing. These products were subcloned into the pGEM-T vector (Promega, Madison, WI, USA) and at least three independent clones were sequenced using a cycle sequencing kit containing 7-deaza-dGTP (Amersham International plc, Buckinghamshire, UK) with an automated DNA sequencer (DSQ1000L: Shimadzu, Co., Tokyo).

\section{Statistical analysis}

When allele frequency distortion was observed between the three groups (SLE, other autoimmune diseases and normal) by $\chi^{2}$ test, we used the Chi-squared test of independence to compare subjects with and without mutations in the glucocorticoid receptor gene. Differences at $p<0.05$ were considered statistically significant.

\section{Results}

We screened exons 5, 7, and 9 for GR gene mutations in samples from 66 patients with SLE, 54 with autoimmune diseases other than SLE and 52 healthy controls. PCR-SSCP analysis revealed mutations, detected as extra bands, only in exon 9 

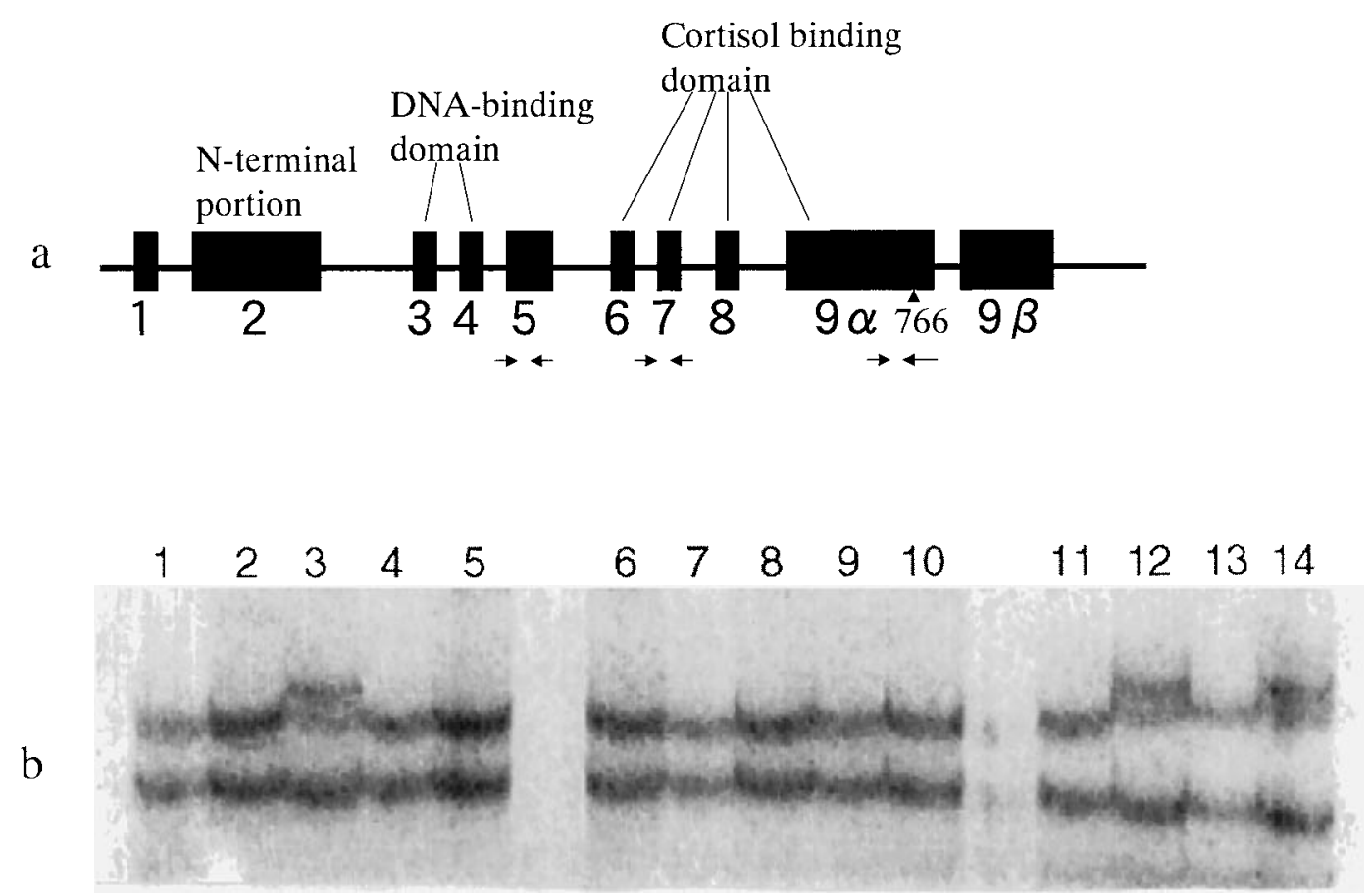

Fig. 1. Map of the glucocorticoid receptor (GR) gene (a) and detection of mutations in exon 9 of the GR gene by PCR-SSCP analysis (b).

B: Lanes 3, 12, 14, mutated type; lanes 1-2, 4-11 and 13, wild type.

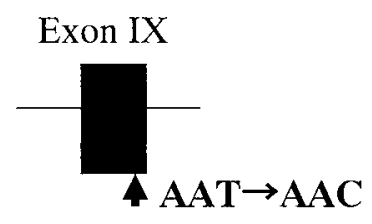

Normal

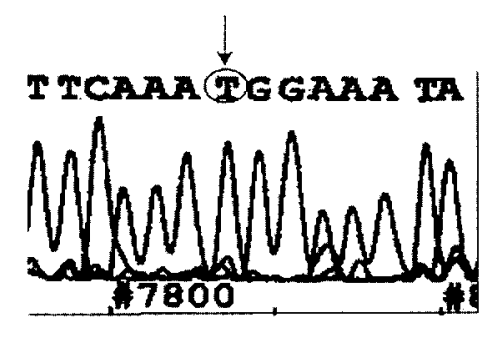
766
TCA AAT GGA
Ser Asn Gly

Patient

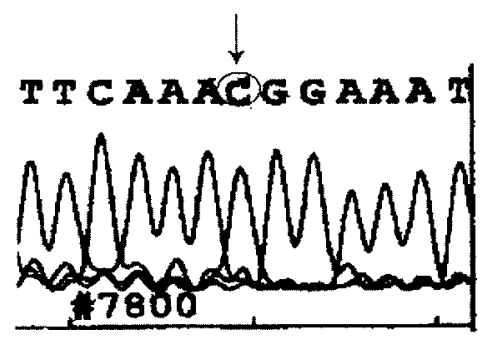

766

TCA AAC GGA

Ser Asn Gly

Fig. 2. Partial nucleotide sequence of exon 9 in the region surrounding codon 766 , amplified from patients and from a control.

The mutation site is underlined in the DNA sequence. 


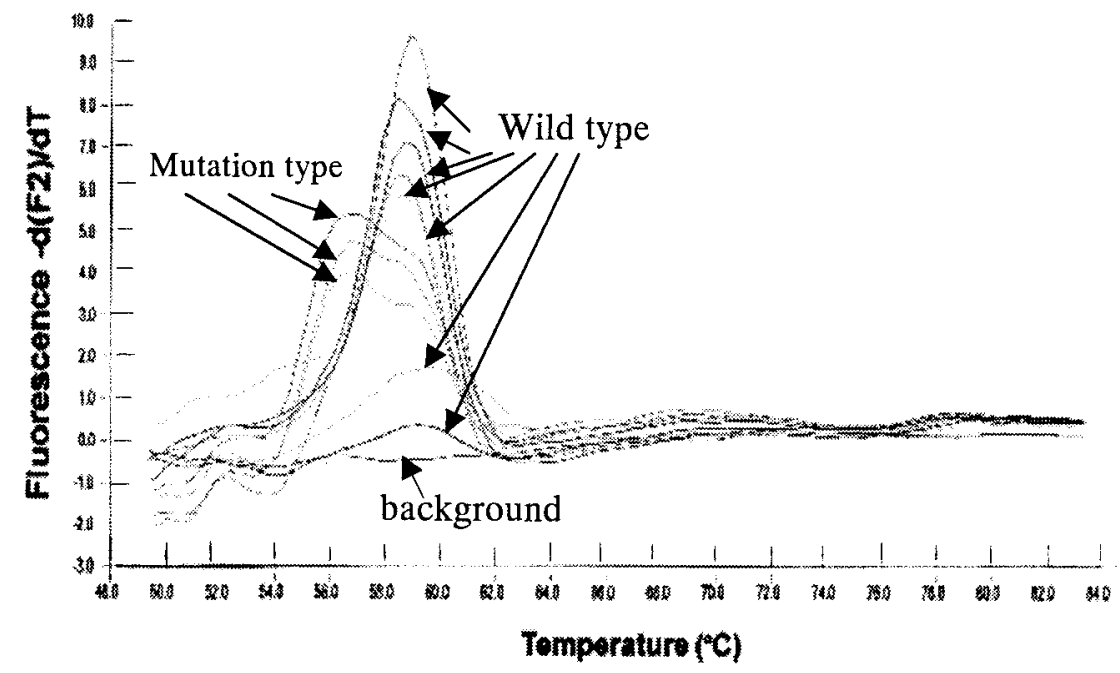

Fig. 3. Derivative melting curves from the LightCycler system, showing two genotypes detected.

The relative change in the fluorescence curve during the cycles is shown on the Y axis. The fluorescence data for the eight samples with mutations (arrow) differ from those for normal controls.

TABLE 2. Allele frequencies of this mutation

\begin{tabular}{lcccc}
\hline \multicolumn{1}{c}{ Group(n) } & Base alteration & Allele frequency & $\chi^{2}$ values & $p$ values \\
\hline SLE (66) & $766 \mathrm{~T} / \mathrm{C}$ & $11 / 132(0.083)$ & 10.01253 & 0.006696 \\
Other autoimmune & $766 \mathrm{~T} / \mathrm{C}$ & $4 / 108(0.034)$ & 3.784367 & 0.051733 \\
Disease (54) & & & & \\
Normal (52) & $766 \mathrm{~T} / \mathrm{C}$ & $0 / 104(0.0)$ & & \\
\hline
\end{tabular}

of the GR gene in 11 patients with SLE and 4 patient with autoimmune diseases other than SLE (2 with MCTD, one with AOSD and one with SLElike symptoms), but not in the 52 normal controls (Fig. 1). We did not detect any differences in exons 5 or 7 of the gene (data not shown). Sequencing showed alteration of the nucleotide at position 2430 in codon 766 in only 8 of the 13 PCR-SSCP positive samples (Fig. 2). This mutation in exon 9 was a silent $\mathrm{T}$ to $\mathrm{C}$ point mutation (AAT to AAC, both encoding asparagine). Furthermore, LightCycler analysis showed different melting curves, indicating the presence of the mutation (Fig. 3). The presence of two broad peaks in the melting curves showed that the patients with this mutation were all heterozygous. The curves also confirmed the absence of the mutation in all of the healthy individuals.
The $\chi^{2}$ test for allele frequencies was used to compare the SLE and other autoimmune disease samples with normal subjects, the control group in this study. The contingency tables revealed significant association between this mutation and SLE, but no association with other autoimmune diseases (Table 2).

\section{Discussion}

Although mutations or polymorphisms in the GR gene may not always reflect the results of in vitro function assays (Soufi et al. 1995), it has been proposed that mutations of codon 641 in exon 7 of the GR gene might be responsible for reduced glucocorticoid sensitivity (Hurley et al. 1991), and that a microdeletion in exon 7 of the GR gene could cause glucocorticoid resistance (Karl et al. 1993). We performed PCR-SSCP 
analysis on regions where mutations in the GR gene are known to occur and found a change in codon 766 of exon 9 only in patients with SLE. Sequence analysis showed that this base change was a heterozygous mutaion. However, we clearly cannot exclude the possibility that this mutation affects splicing or methylation. A mutation in this area has previously been demonstrated in one patient with chronic lymphocytic leukemia (Soufi et al. 1995). However, the relationship of this silent mutation at position 2430 to the physiology or pathological characteristics of the GR is unknown. Koper et al. also detected the same mutation of codon 766 in 11 of 80 (13.7\%) elderly people, showing an association with glucocorticoid resistance as assessed by the dexamethasone suppression test (Koper et al. 1997). However, the mutation of the GR gene demonstrated here was predominantly in younger patients with SLE. This discrepancy may be due to differences in sex (Hurst and Ellegren 1998) or race (Ott et al. 1997), or to the increased prevalence of methylation associated with aging (Ahuja et al. 1998; Post et al. 1999). Although the mutation of the GR gene in patients with SLE is silent, it may represent a polymorphism associated with SLE. T cells produce lower than normal levels of IL-2 in SLE (Russel et al. 1991; Tsokos et al. 1992), and the impaired activity of IL-2 seen in SLE may be associated with steroid sex hormones (Suzuki et al. 1996). In patients with SLE, GR levels are significantly higher than those in healthy controls (Gladman et al. 1991). Although the molecular link between $\mathrm{T}$ cell function and glucocorticoid sensitivity remains unknown (Kam et al. 1993), an inheritable mutation in the GR gene may be responsible for the clinical phenotype or the magnitude of the immune response associated with this disorder. The pathogenesis of SLE is thought to be related to intrinsic hyposensitivity to glucocorticoid secreted by the adrenal gland, impairing the regulation of the immuno-neuro-endocrine axis (Jiang et al. 2001). Exon 9 of the GR gene is located in the $\mathrm{C}$ domain of the receptor, which has ligand binding functions (Warriar et al. 1994).
Further studies should address how mutation of codon 766 in exon 9 influences the expression, structure, and function of the GR, contributing to better understanding of the mechanisms of glucocorticoid resistance and the pathogenesis of SLE.

Another finding of this report was the usefulness of the LightCycler system in screening for the prevalence of mutations in genes, which is becoming increasingly important for the understanding of various diseases. PCR-SSCP analysis is likely to become a standard procedure for this purpose, and is currently the most common method of detecting unknown sequence changes (Hayashi 1993). However, among the 13 extra bands in exon 9 of the GR gene detected by this method, 5 were wild type indicating that PCRSSCP is not the optimal method for detecting putative SLE mutations. New methods such as TaqMan chemistry (De Kok et al. 1998) and the LightCycler system (Wittwer et al. 1997) can detect mutations accurately without gel electrophoresis. We developed a homogeneous assay using a closed tube that allowed rapid genotyping with the LightCycler, and used it to identify homozygotes or heterozygotes for the GR gene. This assay involves allele-specific analysis of probe melting curves on completion of amplification. In contrast with the PCR-SSCP, the results obtained with the LightCycler system were consistent with those of sequencing. Genotyping with the LightCycler system is rapid and reliable, and is suitable for typing large numbers of samples.

The present study focused on a silent mutation in codon 766 of the GR gene in patients with SLE. Whether this change represents a simple mutation or is related to the development of glucocorticoid resistance in SLE patients remains unknown. We cannot say whether this mutation is involved in the etiology of SLE, but it is possible that it is one of several causative factors. Further investigations are therefore needed to determine whether this mutation is a sensitive genetic indicator for variability in treatment responsiveness of SLE. 


\section{References}

Ahuja, N., Li, Q., Mohan, A.L., Baylin, S.B. \& Issa, J.P. (1998) Aging and DNA methylation in colorectal mucosa and cancer. Cancer Res., 58, 5489-5494.

Arkachaisri, T. \& Lehman, T.J. (1999) Systemic lupus erythematosus and related disorders of childhood. Curr. Opin. Rhematol., 11, 384-392.

Bamberger, C.M., Else, T., Bamberger, A.M., Beil, F.U. $\&$ Schulte, H.M. (1997) Regulation of the human interleukin-2 gene by the alpha and beta isoforms of the glucocorticoid receptor. Mol. Cell. Endocrinol., 136, 23-28.

Crispin, J.C. \& Alcocer-Varela, J. (1998) Interleukin-2 and systemic lupus erythematosus-fifteen years later. Lupus, 7, 214-222.

De Kok, J.B., Hendriks, J.C., van Solinge, W.W., Willems, H.L., Mensink, E.J. \& Swinkels, D.W. (1998) Use of real-time quantitative PCR to compare DNA isolation methods. Clin. Chem., 44, 2201-2204.

De Lange, P., Koper, J.W., Huizenga, N.A., Brinkmann, A.O., de Jong, F.H., Karl, M., Chrousos, G.P. \& Lamberts, S.W. (1997) Differential hormone-dependent transcriptional activation and -repression by naturally occurring human glucocorticoid receptor variants. Mol. Endocrinol., 11, 1156-1164.

Gaffney, P.M., Kearns, G.M., Shark, K.B., Ortmann, W.A., Selb, S.A., Malmgren, M.L., Rohlf, K.E., Ockenden, T.C., Messner, R.P., King, R.A., Rich, S.S. \& Behrens, T.W. (1998) A genomewide search for susceptibility genes in human systemic lupus erythematosus sib-pair families. Proc. Natl. Acad. Sci. USA, 95, 14875-14879.

Garred, P., Madsen, H.O., Halberg, P., Petersen, J., Kronborg, G., Svejgaard, A., Andersen, V. \& Jacobsen, S. (1999) Mannose- binding lectin polymorphisms and susceptibility to infection in systemic lupus erythematosus. Arthrits, Rheum., 42, 2145-2152.

Gladman, D.D., Urowitz, M.B., Doris, F., Lewandowski, K. \& Anhorn, K. (1991) Glucocorticoid receptors in systemic lupus erythematosus. J. Rheumatol., 18, 681-684.

Hayashi, K. (1993) PCR-SSCP: A method for detection of mutations. Genet. Anal. Tech. Appl., 9, 73-79.

Helmberg, A., Auphan, N., Caelles, C. \& Karin, M. (1995) Glucocorticoid-induced apoptosis of human leukemia cells is caused by the repressive function of the glucocorticoid receptor.
EMBO J., 14, 452-460.

Hurley, D.M., Accili, D., Stratakis, C.A., Karl, M., Vamvakopoulos, N., Rorer, E., Constantine, K., Taylor, S.I. \& Chrousos, G.P. (1991) Point mutation causing a single amino acid substitution in the hormone binding domain of glucocorticoid receptor in familial glucocorticoid resistance. J. Clin. Invest., 87, 680-686.

Hurst, L.D. \& Ellegren, H. (1998) Sex biases in the mutation rate. Trend. Genet., 14, 446-452.

Jiang, T., Liu, S., Tan, M., Huang, F., Sun, Y., Dong, X., Guan, W., Huang, L. \& Zhou, F. (2001) The phase-shift mutation in the glucocorticoid receptor gene: potential etiologic significance of neuroendocrine mechanisms in lupus nephritis. Clin. Chim. Acta, 313, 113-117.

Kam, J.C., Szefler, S.J., Surs, W., Sher, E.R. \& Leung, D.Y. (1993) Combination IL-2 and IL-4 reduces glucocorticoid receptor-binding affinity and $\mathrm{T}$ cell response to glucocorticoid. J. Immunol., 151, 3460-3466.

Karl, M., Lamberts, S.W., Detera-Wadleigh, S.D., Encio, I.J., Stratakis, C.A., Hurley, D.M., Accili, D. \& Chrousos, G.P. (1993) Familial glucocorticoid resistance caused by a splice site deletion in the human glucocorticoid receptor gene. J. Clin. Endocrinol. Metab., 76, 683-689.

Karl, M., Von Wichert, G., Kempter, E., Katz, D.A., Reincke, M., Monig, H., Ali, I.U., Stratakis, C.A., Oldfield, E.H., Chrousos, G.P. \& Schulte, H.M. (1996) Nelson's syndrome associated with a somatic frame shift mutation in the glucocorticoid receptor gene. J. Clin. Endocrinol. Metab., 81,124-129.

Koper, J.W., Stolk, R.P., de Lang, P., Huizenga, N.A.T.M., Molijn, G-J., Pols, H.A.P., Grobbee, D.E., Karl, M., de Jong, F.H., Brinkmann, A.O. \& Lamberts, S.W.J. (1997) Lack of association between five polymorphisms in the human glucocorticoid receptor gene and glucocorticoid resistance. Hum. Genet., 99, 663-668.

Marion, T.M., Tillman, D.M., Krishnan, M.K., Desai, D.D., Jou, N.T. \& Ruff, M.B. (1994) Immunoglobulin variable-region structures in immunity and autoimmunity to DNA. Tohoku. J. Exp. Med., 173, 43-63.

Moser, K.L., Gray-McGuire, C., Kelly, J., Asundi, N., Yu, H., Bruner, G.R., Mange, M., Hogue, R., Neas, B.R. \& Harley, J.B. (1999) Confirmation of genetic linkage between human systemic lupus erythematosus and chromosome 1q41. Arthritis. Rheum., 42, 1902-1907. 
Northrop, J.P., Crabtree, G.R. \& Mattila, P.S. (1992) Negative regulation of interleukin 2 transcription by the glucocorticoid receptor. J. Exp. Med., 175, 1235-1245.

Ott, R., Waye, J.S. \& Chang, P.L. (1997) Evolutionary origins of two tightly linked mutations in arylsulfatase-A pseudodeficiency. Human Genet., 101, 135-140.

Post, W.S., Goldshmidt-Clermont, P.J., Wilhide, C.C., Heldman, A.W., Sussman, M.S., Ouyang, P., Milleken, E.E. \& Issa, J.P. (1999) Methylation of the estrogen receptor gene is associated with aging and atherosclerosis in the cardiovascular system. Cardiovasc. Res., 43, 985-991.

Russel, J.H., White, C.L., Loh, D.Y. \& Meleedy-Rey, P. (1991) Receptor stimulated death pathway is opened by antigen in mature T cells. Proc. Natl. Acad. Sci. USA, 88, 2151-2153.

Schwartzman, R.A. \& Cidlowski, J.A. (1994) Glucocorticoid-induced apoptosis of lymphoid cells. Int. Arch. Allergy Immunol., 105, 347-354.

Shai, R., Quismorio, F.P., Jr., Li, L., Kwon, O.J., Morrison, J., Wallance, D.J., Neuwelt, C.M., Braubar, C., Gauderman, W.J. \& Jacob, C.O. (1999) Genome-wide screen for systemic lupus erythematosus susceptibility genes in multiplex families. Hum. Mol. Genet., 8, 639-644.

Soufi, M., Kaiser, U., Schneider, A., Beato, M. \& Westphal, H.M. (1995) The DNA and steroid binding domains of the glucocorticoid receptor are not altered in mononuclear cells of treated CLL patients. Exp. Clin. Endocrinol., 103, 175-183.

Suzuki, N., Suzuki, T. \& Sakane, T. (1996) Hormones and lupus: defective dehydroepiandrosterone activity induces impaired interleukin-2 activity of T lymphocytes in patients with SLE. Annal. de Med. Int., 147, 248-252.

Talal, N., Dauphinee, M.J. \& Wofry, D. (1982) Interleukin-2 deficiency, gene and SLE. Arthritis Rheum., 25, 838-842.

Tsao, B.P., Cantor, R.M., Grossman, J.M., Shen, N., Teophilov, N.T., Wallance, D.J., Arnett, F.C., Hartung, K., Goldstein, R., Kalunian, K.C., Hahn, B.H. \& Rotter, J.I. (1999) PARP alleles within the linked chromosomal region are associated with systemic lupus erythematosus. $J$. Clin. Invest., 103, 1135-1140.

Tsokos, G.C. (1992) Lymphocyte abnormalities in human lupus. Clin. Immnol. Immunopathol., 63, 7-9.

Warriar, N., Yu, C. \& Govindan, M.V. (1994) Hormone binding domain of the human glucorticoid receptor. J. Biol. Chem., 264, 2901029015.

Wittwer, C.T., Ririe, K.M., Andrew, R.V., David, D.A., Gundry, R.A. \& Balis, U.J. (1997) The LightCycler: a microvolume multisample fluorimeter with rapid temperature control. Biotechniq., 22, 176-181. 